\title{
EJERCICIOS LINGÜÍSTICOS DE ANTONIO MACHADO
}

\author{
Antonio Aranda Ortiz
}

\begin{abstract}
Todo artista, mejor diré, todo trabajador tiene una filosofía de su trabajo, reflexiones sobre la totalidad de aquella labor a que - como maestro o como aprendiz- se consagra. ¿Por qué hurtarla a los ojos del vecino? Esta filosofía, como aquel trabajo, se debe también a los demás ${ }^{1}$.
\end{abstract}

1. Consagrado - como maestro, sin duda - a una labor de poeta largamente meditada, A. Machado mostró siempre un vivo empeño por dar a conocer la filosofía de su trabajo. Razones para ello encontró, al parecer, varias: de valor relativo, según nos dice, la de responder a los reparos que algunos críticos habían puesto a su obra y a su ideario estético (COMPL., p. 160); de mayor alcance, la de diferenciarse como «verdadero poeta del mero señorito que compone versos», en el entendimiento de que el primero debe explicar, con claridad y por separado, la metafísica inherente a sus poemas (OPP., p. 322); de alcance general, en fin, la razón que encabeza nuestro estudio, esto es, el convencimiento de que la exposición de las reflexiones sobre el propio quehacer constituye, para cualquiera, una obligación hacia los otros.

1 Antonio Machado, Los complementarios, edición de Manuel Alvar (Madrid: Cátedra, 1982), p. 160. En adelante, la referencia a las citas del poeta se insertará entre paréntesis en el texto: si se trata de citas procedentes de Los complementarios, la referencia COMPL. remitirá a la edición que acabamos de mencionar; en cambio, para las citas procedentes de otros escritos de Antonio Machado, la referencia será OPP. y remitirá a la que pretendió ser una edición de sus obras completas, publicada por Aurora de Albornoz y Guillermo de Torre bajo el título de Obras. Poesía y prosa (Buenos Aires: Losada, 1964). 
Al cumplimiento de tal obligación dedicó A. Machado buena parte de sus prosas (De un cancionero apócrifo, numerosos textos de Los complementarios y de Juan de Mairena, prólogos, reseñas, cartas, etc.) y alguno que otro de sus versos (aforismos donde el poeta sintetiza sus ideas fundamentales sobre la lírica), proporcionándonos un conjunto de escritos cuya lectura ha llegado a considerarse imprescindible para la justa valoración de la poesía machadiana ${ }^{2}$. Se trata, por supuesto, de escritos bastante conocidos y reiteradamente comentados, que «autorizan —en opinión de M. Alvar - a establecer una teoría poética bien trabada y bien pensada ${ }^{3}$. Pero el establecimiento de esta teoría dista de ser ya una tarea plenamente concluida: requiere, todavía, un mayor conocimiento y nuevos comentarios de aquellos escritos, debido, sobre todo, a que «Machado no era hombre que exponía sus ideas por sistemas, sino por retazos o fragmentos» ${ }^{4}, \mathrm{y}$ resulta labor difícil, como advierte A. de Albornoz, la sistematización objetiva de un pensamiento que no pretende ser sistemático ${ }^{5}$.

Con el propósito de contribuir, siquiera sea parcialmente, a esa labor sistematizadora, nuestro trabajo revisará unos cuantos retazos o fragmentos del pensamiento de A. Machado que desempeñan, según entendemos, un papel de gran importancia en el conjunto de sus reflexiones, $y$, sin embargo, suelen pasar casi desapercibidos a los comentaristas. Revisaremos, concretamente, algunos análisis lingüísticos efectuados por el poeta para desarrollar una de sus ideas más obsesivas: la referida a las relaciones de la lengua poética con la lengua funcional.

2. A juzgar por su propia producción literaria, A. Machado parece entender que tales relaciones son muy estrechas, dado que no gusta de fijar grandes distancias entre la lengua que elabora con intención estética y la lengua de todos; más bien al contrario, busca siempre una directa aproximación de ambas. Así lo ha reconocido insistentemente la crítica, tanto cuando asegura, de forma general, que «Machado crea una poesía sustancialmente subjetiva, cargada con elementos de su vida emocional y transmitida por procedimientos sencillísimos, pero insustituibles en su aparente sencillez» ${ }^{6}$, como cuando, atendiendo en particular a los aspectos formales, subraya que en esa poesía «la palabra común parece haber sufrido un mínimo de alteración» ${ }^{7}$.

No obstante, la sencillez de los procedimientos lingüísticos empleados por el poeta es sólo un hecho, de fácil comprobación, que por sí mismo no nos dice cómo concebía A. Machado la naturaleza de la lengua poética, ni hasta qué punto se preocupaba de relacionarla más o menos con la lengua funcional. En este sentido, su creación literaria resulta tan poco explícita como la de cualquier otro

2 Véase la Introducción de Geoffrey Ribbans a la edición de Soledades. Galerías. Otros poemas (Madrid: Cátedra, 1983), p. 21.

3 Manuel Alvar, Introducción a la edición de Los complementarios registrada en nota 1, pp. 11-12.

4 Ramón de Zubiría, La poesía de Antonio Machado (Madrid: Gredos, 1981), p. 103.

5 Aurora de Albornoz. Notas preliminares a la Antología de la prosa de A. Machado, vol. II: Literatura y Arte (Madrid: Edicusa, 1976), pp. 7-8.

6 Manuel Alvar, op. cit., p. 21.

7 Ricardo Gullón, Una poética para Antonio Machado (Madrid: Gredos, 1970), p. 16. 
autor, y no permite asegurar que la mínima alteración experimentada por la palabra común sea la plasmación, conscientemente perseguida, de una determinada concepción de lengua poética ideal: en primer lugar, porque podría no existir tal concepción, como sugieren «quienes todavía persisten en considerar la poesía de Machado como una especie de flor de espontaneidad, producto milagroso de una inspiración fácil y regalada, en la que apenas interviene la labor incansablemente rectificadora del verdadero artista ${ }^{8}$; en segundo lugar, y sobre todo, porque el mismo A. Machado advierte que «la página escrita nunca recuerda todo lo que se ha intentado, sino lo poco que se ha conseguido» (OPP., p. 45), y cabe, por tanto, la posibilidad de que tuviese un ideal de poesía con mayor complicación lingüística que la reflejada en sus poemas, es decir, la posibilidad de que hubiese buscado, sin conseguirla, una más intensa alteración de la palabra común.

La producción poética de A. Machado nos sitúa, pues, frente a un lenguaje literario de gran sencillez, pero no nos lleva a saber si es, o no, consciente y voluntaria la simplicidad de los mecanismos lingüísticos utilizados en la elaboración de ese lenguaje. Para despejar esta duda, hay que acudir a la otra vía que dejó abierta el poeta: la de su ideario estético, donde nos da las claves para resolver cuantos interrogantes pudiera suscitar su creación, haciéndonos saber, en general, de sus propósitos, y, en particular, del grado de intencionalidad existente en la sencillez formal de sus poemas.

2.1. Alternativa y paralela a la vía de la creación, esta otra de la reflexión ha descubierto a la crítica la existencia de un ideal poético laboriosamente definido, que invalida cualquier consideración de la lírica machadiana como producto espontáneo de una inspiración fácil, obligando a interpretarla, en cambio, como fruto de una elaboración mesurada y pacientísima ${ }^{9}$. La crítica se ha encontrado, en efecto, frente a un pensamiento constantemente interesado en la naturaleza de la poesía y de la lengua poética, y ha procedido a contrastarlo con los versos de A. Machado hasta comprobar «que entre su concepto de poesía y su poesía - o, al menos, en buena parte de ella - hay una perfecta concordancia» ${ }^{10}$.

La concordancia afecta, particularmente, a la escasa artificiosidad lingüística de aquellos versos, donde no cabe ver, en absoluto, el fracaso de ninguna intención; ha de verse, por el contrario, el reflejo consciente y voluntario del ideal de lengua poética propugnado por quien sostuvo, en más de una ocasión, que «el encanto inefable de la poesía, que es, como alguien certeramente ha señalado, un resultado de las palabras, se da por añadidura en premio a una expresión justa y directa de lo que se dice» (OPP., pp. 516 y 841). Tal debió ser, para A. Machado, la formulación más acabada del ideal de lengua poética implícito en sus poemas, cuando la utilizó más de una vez sin alterarle los términos. Pero no fue, desde luego, la única observación del poeta sobre la naturaleza de la expresión lírica.

2.2. En el ideario estético de A. Machado, las indicaciones referidas a esta cuestión son, ciertamente, muy numerosas, y aparecen bajo las formas más di-

8 Ramón de Zubiría, op. cit., pp. 13-14.

9 Geoffrey Ribbans, op. cit., p. 31.

10 Aurora de Albornoz, op. cit., p. 13. 
versas: a veces tienen el aspecto de formulación de principios generales, otras veces se presentan como consejos a poetas o aprendices de poeta, y, en ocasiones, adquieren incluso la apariencia de ejercicios realizados por Mairena y sus alumnos en las clases de Retórica y Poética. Así, el enunciado que hemos visto dedicado a consagrar la expresión justa y directa como condición indispensable para lograr el encanto inefable de la poesía, se convierte en consejo dirigido a otros poetas con estos términos: «sobre la claridad he de deciros que debe ser vuestra más vehemente aspiración» (OPP., p. 502); a su vez, ese consejo parece prolongarse en una advertencia sobre cómo buscar la expresión justa y clara, cuando A. Machado manifiesta a Gerando Diego su convicción de «que el poeta necesita para producir, oir la lengua pura y viva» (OPP., p. 932); y la advertencia, en fin, cobra forma de ejercicio práctico con Mairena, en aquella clase bien conocida donde se registra el siguiente diálogo:

- Señor Pérez, salga usted a la pizarra y escriba: «Los eventos consuetudinarios que acontecen en la rúa».

El alumno escribe lo que se le dicta.

- Vaya usted poniendo eso en lenguaje poético.

El alumno, después de meditar, escribe: «Lo que pasa en la calle».

Mairena.- No está mal. (OPP., p. 351).

De todas estas fórmulas, y aun de otras, se sirve A. Machado para mostrar que su poesía respondió siempre a un mismo concepto de expresión lírica, y para intentar, al menos, precisarnos cómo se aproxima ese concepto de expresión directa y clara a la lengua funcional, sin llegar a confundirse con ella. Sin embargo, quizá esta última precisión se vio entorpecida por la diversidad de formas que A. Machado dio a su pensamiento, y, en particular, porque las reflexiones que aparecen a la manera de simples ejercicios de clase se muestran propicias a una interpretación igualmente simple que, con frecuencia, resulta errónea. En este sentido apunta R. de Zubiría cuando, tras advertir que «hay quienes creen - los más ingenuos, naturalmente- que la claridad, para él, consistía en expresarse en el lenguaje corriente», puntualiza que la lectura poco atenta de la clase de Mairena recogida arriba puede explicar, en cierto modo, aquella creencia ingenua, pero nunca justificarla, dado que A. Machado «ni por un momento identifica el lenguaje poético con le lenguaje corriente» ${ }^{11}$.

2.3. Si al comenzar nuestro trabajo señalábamos que los ejercicios lingüísticos efectuados por el poeta -y trasladados, las más de las veces, a las clases de Mairena- pasan, por lo general, casi desapercibidos a los comentaristas, ahora podemos añadir que, cuando se les atiende, parecen más proclives a confundir que a clarificar el pensamiento de A. Machado. Pero esta constatación no disminuye, sino incrementa, nuestro convencimiento de que los análisis prácticos tienen una importancia considerable en el conjunto de las reflexiones machadianas, al tiempo que pone de manifiesto la necesidad de prestar mayor atención a tales análisis, aunque sólo sea para evitar las confusiones que originan.

11 Ramón de Zubiría, op. cit., p. 151. 
En teoría, los ejercicios concretos sobre diferentes aspectos de la lengua no son más que retazos — menores o marginales, si se quiere- del pensamiento poético de A. Machado, destinados por éste, según entiende P. Cerezo, a mostrar «el logro de una expresión directa y simple, con un profundo acento de temporalidad o de experiencia vivida, de acuerdo con sus propias premisas poéticas» ${ }^{12}$. En teoría, por tanto, aquellos ejercicios debieran ser un desarrollo clarificador de estas premisas - entre las cuales, veremos (cf. 3.3), se encuentra explícitamente la que distingue, aunque estén próximas, la expresión poética de la común-, y no un elemento perturbador en la captación de las mismas. Sucede, sin embargo, que la relación entre premisas generales y análisis particulares queda, a menudo, poco clara, por la especial configuración del pensamiento machadiano, profundamente escéptico, que el poeta, en su modestia, atribuye a la falta «de un cerebro más vigoroso, dotado de más circunvoluciones y vías asociativas, con mayor cultura asimilada y hábitos de mayor continuidad en el discurso» (COMPL., p. 160).

No sabemos hasta qué punto A. Machado echó a faltar, realmente, ese cerebro más vigoroso, pero sí que fue siempre «uno de esos escépticos radicales que no se conforman con una sola y definitiva explicación de un problema. Encarado con uno, lo sitiaba por todas partes, buscándole desesperadamente una solución que casi nunca encontraba, pero de cuyo asedio quedaban siempre algunas ideas provocativas» ${ }^{13}$. Es lo que ocurre, concretamente, con el problema de la lengua poética y sus relaciones con la lengua funcional: en el cerco al que A. Machado lo somete, probablemente no encontremos ninguna solución definitiva; pero sí una serie de ideas en cierto modo provocativas, más por la dificultad de conjuntarlas que por la existencia de ninguna contradicción real entre las mismas.

Se debe, no obstante, superar la dificultad, y puede hacerse si, además de reconocer el carácter fragmentario de un pensamiento que se exterioriza en observaciones múltiples y diversas en su forma, tratamos de averiguar cómo se vincula cada una de esas notas con las restantes. No cabe, ciertamente, extraer la conclusión, demasiado fácil, de que con el diálogo de Mairena que antes vimos A. Machado identifica la lengua poética con la común, contradiciendo una de sus premisas fundamentales; se ha de ver, más bien, que ese diálogo no constituye un episodio único y aislado en el ideario estético de A. Machado, sino que guarda una profunda similitud, con otro de los ejercicios propuestos por Mairena para ejemplificar lo que considera una amplificación superflua:

- Daréte el dulce fruto sazonado del peral en la rama ponderosa.

- ¿Quieres decir que me darás una pera?

- ¡Claro! (OPP., p. 477).

Aunque la observación simultánea de ambos ejercicios parece confirmar, más que desmentir, la idea de que A. Machado defiende un tipo de expresión poética

12 Pedro Cerezo, Palabra en el tiempo (Poesía y filosofía en Antonio Machado) (Madrid: Gredos, 1975), p. 458.

13 Ramón de Zubiría, op. cit., pp. 103-104. 
prácticamente idéntico a la expresión común, el proceso de integración de sus reflexiones, lejos de detenerse aquí, debiera proseguir para verificar que el último diálogo, a su vez, sigue y se contrapone a otro ejercicio práctico donde se ejemplifica la concisión barroca:

Me dio cuatro naturales y en Chihuahua clarecí.

Aquí ya la expresión inexacta es, por su excesiva concisión, verdaderamente enigmática. Porque el poeta, cuyos son estos versos, quería decir, por boca de un personaje de su comedia: «El cacique de la comarca puso a mi servicio cuatro hombres nacidos en tierras americana, cuatro indígenas que me dieron escolta, y acompañado de ellos pude llegar felizmente a Chihuahua, a la hora en que empezaba a clarear». (OPP., pp. 476-477).

2.4. Vistos en su conjunto los tres ejercicios, aún podríamos seguir manteniendo que todos ellos nos muestran una expresión justa y clara nada diferente de la coloquial. Pero tendríamos que matizar esa idea, porque, al ampliarse el número de ejercicios que encontramos relacionados, también se ensancha la comprensión de los mismos en, al menos, dos sentidos fundamentales. En primer lugar, empezamos a ver que A. Machado no sólo analiza determinadas expresiones de todos y de nadie, sino que enjuicia otras expresiones reconocidas como poéticas, tratando de establecer su ideal de expresión justa y directa tanto con relación a la lengua funcional como, tal vez, por reacción contra la lengua de ciertos poetas. En segundo lugar, también empezamos a constatar que el problema de la expresión se hace cada vez más complejo, pues si los dos primeros diálogos únicamente hacían pensar en que la claridad expresiva se obtiene por eliminación de los elementos superfluos, con el último ejercicio se hace obligado pensar hasta dónde puede llegar la eliminación de elementos sin que distorsione la claridad de la expresión.

La complejidad de lo que fue, para A. Machado, el problema de la expresión aumenta cuando comprobamos que no todo se reduce, como dejan entrever los ejercicios hasta aquí considerados, a una cuestión de expresiones más o menos amplias o concisas. Hay que considerar, junto a éstos, otros análisis concretos donde el poeta pone de manifiesto que, para dar con la expresión justa y directa de lo que se dice, es necesario profundizar en aspectos lingüísticos tan diversos como puedan ser el significado de las palabras (véase el comentario de los vocablos entelequia y autobús, en OPP., pp. 366 y 504, respectivamente), las diferencias denotativas (véase el análisis distribucional de comer tomate con judías/os y comer judías/-os con tomate, en COMPL., p. 81, modificado luego para Mairena, en OPP., p. 355) y connotativas (véase el contraste de mi mujer-mi señora / mi hombre, en OPP., p. 539) que se obtienen según sus combinaciones, las interferencias semánticas motivadas por similitudes fonéticas (véase la conversión de clavícula en canícula, comentada en OPP., p. 477), etcétera.

La lectura poco atenta $y$, frecuentemente, aislada de cada uno de estos u otros ejercicios particulares, no permite, por supuesto, conocer cómo concebía A. Machado la lengua poética ideal, ni por qué y hasta dónde trataba de aproximarla 
a la lengua común. Sin embargo, si se contemplan en su conjunto, esos ejercicios podrían contarse entre las reflexiones más clarificadoras de la concepción que tuvo A. Machado sobre la naturaleza de la lengua poética.

3. Esa concepción, lógicamente, no sólo no puede contemplarse con nitidez en cada uno de los ejercicios que hemos ido mencionando, sino que ha de verse integrada en una comprensión más amplia, global, de la poesía, imposible de revisar aquí detalladamente, pero que debemos retener en lo fundamental porque condiciona y determina las consideraciones específicamente lingüísticas de A. Machado. La mejor síntesis de su comprensión total del hecho poético es, probablemente, la que él mismo dejó en una de las cartas a Guiomar:

La lírica ha sido siempre una expresión del sentimiento, el cual contiene a la sensación —no a la inversa-, y se relaciona con las ideas; se engendró siempre en la zona central de nuestra psique, y nunca pretendió hablar ni a la sensibilidad ni, mucho menos, a la pura inteligencia (OPP., p. 934).

De orientación manifiestamente idealista ${ }^{14}$, esta visión de la lírica destaca los dos elementos constitutivos de la misma, sentimiento y expresión, sobre los cuales reflexionará constantemente A. Machado, centrándose, unas veces, en la especificidad de cada elemento, y fijando, en otras ocasiones, paralelismos e interdependencias fundamentales para ambos. Cada uno de esos elementos plantea problemas muy complejos al poeta que, en el caso del sentimiento, consiste, básicamente, en ubicarlo en la zona central de nuestra psique de la que habla a Guiomar.

3.1. No nos detendremos ahora a precisar como plantea y aborda A. Machado la cuestión del sentimiento, tanto porque se trata de un tema suficientemente estudiado ${ }^{15}$, como porque nos encontraríamos frente a una serie de reflexiones más extensas, seguramente, que la destinada al problema de la expresión. Por lo demás, aquí sólo nos interesa la cuestión del sentimiento en cuanto que se proyecta y afecta a la concepción machadiana de la lengua poética; y, a este respecto, creemos que es suficiente con subrayar los esfuerzos de A. Machado por definir el sentimiento como una de las «formas de comunión humana» equiparable a la del pensamiento lógico, si bien su radio es menor que «el radio infinito de las ideas» (OPP., p. 848), diferenciándolo, al mismo tiempo, de «lo inmediato psíquico, el fluir de la conciencia individual, lo anterior al lenguaje, al pensamiento conceptual y a la construcción imaginativa» (OPP., p. 810).

La cuestión del sentimiento se sintetiza, para lo que nos importa, en que debe suponer un equilibrio entre el caos afectivo del mundo interior y la pura objetividad de las ideas, esto es, que «ha de tener tanto de individual como de genérico porque aunque no existe un corazón en general, que sienta por todos, sino que cada hombre lleva el suyo y siente con él, todo sentimiento se orienta hacia los valores universales o que pretenden serlo» (OPP., pp. 324-325). De hecho, la ela-

14 Sobre el idealismo lingüístico de Antonio Machado, véase Manuel Alvar, op. cit., pp. 18-19; una interpretación diferente del «idealismo» machadiano nos ofrece Pedro Cerezo, op. cit., pp. 268-277.

15 Véase Ramón de Zubiría, op. cit., pp. 140-150; asimismo, Pedro Cerezo, op. cit., pp. 281-330. 
boración del sentimiento constituye, para A. Machado, el primer problema que se le plantea a la lírica, antes de que surja el problema de la expresión:

Mi sentimiento no es, en suma, exclusivamente mío, sino más bien nuestro. Sin salir de mí mismo, noto que en mi sentir vibran otros sentires, y que mi corazón canta siempre en coro, aunque su voz sea para mí la voz mejor timbrada. Que lo sea también para los demás, este es el problema de la expresión lírica. Un segundo problema. Para expresar mi sentir tengo el lenguaje. Pero el lenguaje es ya mucho menos mío que mi sentimiento (COMPL., p. 96).

3.2. Conseguir la voz mejor timbrada, para él y para otros, que le permita exteriorizar un sentir propio y de todos, es, como vemos, el auténtico problema de la expresión lírica. Una expresión que, siendo única y singular del poeta, sólo puede elaborarse con un lenguaje que no le pertenece ni le pertenecerá jamás:

Antes de ser nuestro, porque mío exclusivamente no lo será nunca, era de ellos, de ese mundo que no es ni objetivo ni subjetivo [...], del mundo de los otros yo (COMPL., pp. 96-97).

Desde esta concepción del lenguaje, A. Machado plantea el problema de la expresión lírica en unos términos diferentes, sin duda, pero de idéntico contenido, a los utilizados por el también idealista A. Alonso, cuando asegura: «el lenguaje, como herencia cultural que es, encierra en cada uno de sus elementos, lo mismo que en su sistema íntegro, el recuerdo vitalizado de todas las experiencias nuestras y de nuestros antepasados sobre las cosas. Las más originales intuiciones personales están intervenidas por esas montañas de recuerdos en cuanto se expresan por medio del lenguaje» ${ }^{16}$. Éste, en cada uno de sus elementos y en su sistema íntegro, no impide expresar la intuición personal, lo más hondo del sentimiento, pero la interviene, objetivándola; y el poeta, si pretende que su voz sea la mejor timbrada para los demás, debe respetar la herencia cultural que le sirve como instrumento.

Para A. Machado, la dificultad que ha de encarar el poeta reside en la naturaleza misma de la materia con la que trabaja, radicalmente distinta a la que utilizan otros artistas en sus creaciones. Mientras éstos se enfrentan, generalmente, a «algo no configurado por el espíritu: piedra, bronce, sustancias colorantes, aire que vibra, materia bruta, en suma, de cuyas leyes, que la ciencia investiga, el artista, como tal, nada entiende» (OPP., p. 308), el poeta trabaja con algo sí configurado por el espíritu y necesita conocer las leyes que rigen esa materia porque «las palabras, a diferencia de las piedras, o de las materias colorantes, o del aire en movimiento, son ya, por sí mismas, significaciones de lo humano, a las cuales ha de dar el poeta nueva significación» (OPP., p. 308).

3.3. Es en este punto donde se encuentra, a nuestro entender, la clave para explicar por qué la palabra común parece sufrir un mínimo de alteración en la poesía de A. Machado, por qué éste tiene un ideal de lengua poética muy próxima, pero no idéntica, a la lengua funcional, y, en fin, por qué lleva a cabo, reite-

16 Amado Alonso, «Por qué el lenguaje en sí mismo no puede ser impresionista», en Estudios lingüísticos. Temas españoles (Madrid: Gredos, 1967), pp. 275-6. 
radamente, análisis lingüísticos tan concretos como simples. Que no identifica la expresión poética con la común queda patente cuando, continuando en su reflexión sobre la materia que moldea el poeta, nos dice: «La palabra, es en parte, valor de cambio, producto social, instrumento de objetividad (objetividad en este caso significa convención entre sujetos), y el poeta pretende hacer de ella medio expresivo de lo psíquico individual, objeto único, valor cualitativo. Entre la palabra usada por todos y la palabra lírica existe la diferencia que entre una moneda y una joya del mismo metal» (OPP., p. 308). Sin embargo, también deja constancia, muy evidente, de que la expresión poética no puede distanciarse en exceso de la común cuando, al finalizar su reflexión, advierte: «Pero al poeta no le es dado deshacer la moneda para labrar su joya [...]. Trabaja el poeta con elementos ya estructurados por el espíritu, y aunque con ellos ha de realizar una nueva estructura, no puede desfigurarlos» (OPP., p. 308).

Transformar la palabra, añadirle nueva significación, pero sin desfigurarla, sin eliminarle sus «significaciones de lo humano», éste fue el objetivo que A. Machado intenó plasmar en sus versos.

4. Sobre la consecución de ese fin hay, según vimos (cf. 2.), un acuerdo generalizado entre los críticos. Y en la forma de conseguirlo hay, según entendemos, una aportación fundamental de todos y cada uno de los ejercicios lingüísticos con los que A. Machado buscaba, ante todo, conocer y dar a conocer cómo están estructurados los elementos que ha de transformar el poeta, y cómo éste puede llegar a desfigurarlos si no acepta las leyes que rigen esa estructuración.

Encarado con el problema de la expresión, A. Machado no permanece en el plano de las generalizaciones teóricas, sino que se adentra en el dominio de los análisis pormenorizados para decirnos quiénes y cómo llegaron a desfigurar la palabra, o quiénes y cómo supieron transformarla de acuerdo con su naturaleza. El pensamiento del poeta se bifurca, así, en dos caminos que deja señalados con la siguiente recomendación de Mairena:

Huid del preciosismo literario, que es el mayor enemigo de la originalidad. Pensad que escribís en una lengua madura, repleta de folklore, de saber popular (OPP., p. 383).

Por el primer camino, transitan quienes ignoran «que en poesía — sobre todo en poesía - no hay giro o rodeo que no sea una afanosa búsqueda del atajo, de una expresión directa; que los tropos, cuando superfluos, ni aclaran ni decoran, sino complican y enturbian; y que las más certeras alusiones a lo humano se hicieron siempre en el lenguaje de todos» (OPP., p. 516). Son, para A. Machado, fundamentalmente los poetas barrocos. Por el segundo, en cambio, caminan quienes aludieron a lo humano en el lenguaje de todos porque sabían que, en la lírica, imágenes y metáforas son «de buena ley cuando se emplean para suplir la falta de nombres propios y de conceptos únicos, que requiere la expresión de lo intuitivo, pero nunca para revestir lo genérico y convencional» (COMPL., p. 84). Serán casi siempre, para A. Machado, Jorge Manrique, Fray Luis de León, San Juan de la Cruz y Gustavo Adolfo Bécquer. 
A. Machado nos dirá, además, de qué manera se apartan los primeros de la lengua hasta desfigurar la palabra misma, para explicarnos, por otra parte, cómo los verdaderos poetas se acercan a la lengua de todos antes de intentar cualquier transformación. Y lo hará sirviéndose de ejercicios lingüísticos muy precisos, comparables a los que hemos señalado más arriba.

4.1. En su huída del preciosismo literario, A. Machado se detiene a analizar las expresiones oro cano y plata rubia, en dos momentos diferenciados. Nos ofrece, así, dos versiones relacionadas pero distintas, tan interesantes por sus coincidencias como por sus divergencias.

La primera versión aparece en el cuaderno de Los complementarios, como nota explicativa a la siguiente indicación, que forma parte de un texto sobre las imágenes en la lírica: «Silenciar los nombres directos de las cosas, cuando las cosas tienen nombres directos, ¡qué estupidez!» (COMPL., p. 83). La nota explicativa, que se extiende a lo largo de las páginas 83-85, pretende ser un ejemplo en caricatura del uso artificioso del lenguaje indirecto, y tiene un tono bastante franco que llega a parecer casi agresivo: se habla de «los vulgares juegos metafóricos» en que incurren nuestros clásicos cuando nos proporcionan «metaforas tan estúpidas» como las de púrpura nevada y nieve roja, para designar el alba, la de $p a$ peles azules que alumbran letras doradas, para el cielo estrellado, y las de oro cano y plata rubia para nombrar, respectivamente, la plata y el oro. Son estas dos últimas, tan «elementales cuanto superfluas metáforas», las que centran la atención de A. Machado:

Por una fácil asociación se define el oro como metal rubio la plata como metal cano. Pasan aquí los colores del cabello, con sus valoraciones de juventud y vejez a adjetivar dos metales en el orden también de sus respectivos precios. Oro $=$ metal rubio

Plata $=$ metal cano.

Oro: plata:: juventud: vejez.

Aquí termina todo el trabajo mental de los espíritus que no presumen de sutiles.

4.2. Hasta aquí, A. Machado admite y entiende la fácil asociación de rubio con amarillo y cano con blanco que es, sin duda, la misma que, con sentido inverso, se produce en expresiones metafóricas de uso tan frecuente como cabellos dorados o sienes plateadas. En todos estos casos se registra lo que M. Le Guern llama «suspensión clasemática, que incide sobre los semas contextuales o clasemas» ${ }^{17}$, sin distorsionar gravemente la significación y, mucho menos, el funcionamiento de las categorías «sustantiva» y «adjetiva». Por otra parte, la aplicación de rubio, en lugar de amarillo, a oro, y de cano, en lugar de blanco, a plata, puede justificarse porque comporta «el juicio de valor implícito en la mayoría de las metáforas» ${ }^{18}$, como indica A. Machado, y esta valoración queda vinculada a lo subjetivo, a la intuición. Hay, por tanto, una justificación para estas ex-

17 Michel Le Guern, La metáfora y la metonimia (Madrid: Cátedra, 1976), p. 23.

18 Ídem, p. 114. 
presiones. Sin embargo, frente a los espíritus que no presumen de sutiles, A. Machado encuentra y critica a quienes sí lo hacen:

Pero podemos, sin acrecentar en lo más mínimo nuestro contenido ideológico, continuar nuestro trabajo combinatorio de términos lógicos —definidoshasta lo infinito:

1. Verás la plata rubia, el oro cano.

Lo definidor es ya el adjetivo y, por lo tanto, nuestra mente reconocerá el oro, bajo el nombre de plata, allí donde aparezca la rubicundez y, viceversa, a la plata, a pesar del sustantivo oro, donde el adjetivo cano.

Sólo un papanatas puede pensar que hay ingenio en este trivialísimo juego conceptual, mediante el cual nos apartamos cada vez más de la intuición del oro y de la plata.

Evidentemente, en estos casos el mecanismo metafórico no se queda en una simple suspensión clasematica, pues se pretende distorsionar los semas nucleares del sustantivo y alterar su funcionamiento, que, aunque gramaticalmente sigue siendo el de una categoría primaria, semánticamente más parece el de una categoría secundaria. Por otra parte, no encontramos en plata rubia ni en oro cano ningún juicio de valor implícito, sino un simple enmascaramiento de los nombres de las cosas, que dificulta la comprensión de lo que se dice y nos aleja de cualquier intuición.

A. Machado amplía su análisis con ejemplos cada vez más complejos, manteniendo siempre como base las expresiones plata rubia y oro cano, para mostrar «hasta dónde puede llegar el trabajo estúpido de la mente humana», mediante el encadenamiento de metáforas tan distantes de la expresión del sentimiento como cercanas a lo que, desde la retórica, se ha considerado una exasperación de lo racional ${ }^{19}$.

Cuando años mas tarde A. Machado decidiera publicar este análisis sirviéndose de Mairena, lo presentaría bajo el rótulo de Ejercicios poéticos sobre temas barrocos (OPP., pp. 367-368) y con la finalidad de contraponer lo clásico a lo barroco:

Lo clásico - habla Mairena a sus alumnos- es el empleo del sustantivo, acompañado de un adjetivo definidor [...]. Lo barroco no añade nada a lo clásico, pero perturba su equilibrio, exaltando la importancia del adjetivo definidor hasta hacerle asumir la propia función del sustantivo.

Ya sabemos a qué se refiere A. Machado, pues, en los sustancial, esta versión coincide con la primera. Pero hay diferencias apreciables y de gran interés, motivadas por la necesidad de dar correcta forma literaria a lo que, en Los complementarios, sólo eran borradores y apuntes impublicables: lo que antes pudo parecer agresividad, ahora se transforma en la característica ironía de Mairena que, como otras veces, entabla un diálogo con el alumno Martínez tras hacerle escribir en la pizarra

19 J. Dubois et al., Rhétorique générale (París: Larousse, 1970), p. 111. 
Oro cano te doy, no plata rubia.

- ¿Qué quiere decir eso?

- Que no me da usted oro, sino plata.

- Conformes. ¿Y qué opina usted de ese verso?

- Que es un endecasílabo bastante correcto.

- ¿Y nada más?

- ... La gracia de llamar plata al oro y oro a la plata.

Como en la versión anterior, el ejercicio se amplía con ejemplos cada vez más complicados. Pero basta lo que antecede para señalar lo que interesa: en la primera versión no se menciona ningún metro determinado y, por lo mismo, no hay posibilidad de referirse a su perfección formal. Ahora, en cambio, se nos habla de un endecasílabo bastante correcto, y en los ejemplos que omitimos se hacen otras referencias y juicios métricos. Pura ironía de A. Machado, oculto bajo Mairena: si en su cuaderno personal nos ha hecho ver que falla lo fundamental, la búsqueda de la expresión directa, la alusión certera en el lenguaje de todos, no puede haber corrección formal de ningún tipo y, menos aún, la «gracia de llamar» desfigurando el nombre propio de las cosas que lo tienen. Precisamente, porque el mismo Machado-Mairena ha dejado dicho, en otra parte, que «hay algo a que el barroco ha de renunciar, pues ni la mera apariencia le es dado contrahacer: la calidad de lo gracioso, que sólo se produce cuando el arte, de puro maestro, llega al olvido de sí mismo, y a hacerse perdonar su necesario apartamiento de la naturaleza» (OPP., p. 321).

4.3. La naturaleza, en el caso de la expresión, son las palabras que tienen, por sí mismas, significaciones de lo humano, y que el poeta debe transformar. Para no desfigurarlas, como hemos venido viendo, y hacerse perdonar la alteración, tiene que conocerlas a fondo antes de intentar añadirles su propia significación, dado que «sin la asimilación y el dominio de una lengua madura de ciencia y conciencia popular, ni la obra inmortal ni nada equivalente pudo escribirse» (OPP., pp. 421-422).

Eso es lo que busca A. Machado con cada uno y con todos sus ejercicios lingüísticos: asimilar la lengua, dominarla, para ver cómo puede servirse de ella y cómo puede mejorarla. Con algunos buscará, sobre todo, lo primero, como aquél donde Mairena empieza «por el empleo de adjetivos que añadan algo a lo que, de primeras, pensamos o imaginamos en el sustantivo» (OPP., pp. 397-398), tomando como punto de partida la expresión angel bueno y estableciendo una gradación, cada vez más acentuada, del valor restrictivo o especificativo del adjetivo en angel custodio-guardián-de la espada flamígera, hasta concluir: «Hay mucho que andar, sin salir de los lugares comunes, antes que lleguemos a la expresión nueva y sorprendente, a la adjetivación valiente, que desafía la misma contradictio in adjecto; por ejemplo: ¡un guardia de asalto!...»».

Con otros ejercicios, en cambio, procurará no tanto el ejemplo positivo cuanto el negativo, es decir, no ya encontrar en la lengua el modelo que le lleve a intentar expresiones nuevas y sorprendentes, sino indagar en la misma con el propósito de evitar el maleficio de los lugares comunes, el riesgo de anegar su pensamiento en la expresión trivial y desgastada por el uso. Es lo que sucede con el análisis 
del tópico que ha llegado a ser la expresión canas, siempre venerables (OPP., p. 410), ante la que debe adoptarse una actitud interrogadora y reflexiva, porque el adjetivo, que debiera ser restrictivo o especificativo, ha adquirido un valor casi definidor o explicativo que, de hecho, no le corresponde.

5. La importancia que para nosotros tiene cualquiera de estos tres ejercicios sobre la adjetivación de oro y plata, por un lado, y de angel y canas, por otra parte, no reside en ninguno de ellos aisladamente. Como tampoco en los que revisamos en el segundo apartado de este estudio, dedicados al análisis de la amplificación y la simplificación de las expresiones. Cada uno de esos ejercicios, considerado por sí sólo quizá no conduce más que a interpretar, equivocadamente, que A. Machado identifica la lengua poética con la lengua común. No obstante, vistos en su conjunto, se nos revelan como fragmentos o retazos de otras reflexiones que, sin dejar de ser marginales y secundarios, son, en dos sentidos al menos, bastante ilustrativos.

En primer lugar, ilustran formulaciones generales o premisas establecidas por A. Machado sobre la esencia de la lengua poética: si ésta se concibe como transformación de la lengua funcional, que no puede ser deformada y debe ser asimilada por el poeta, el primer paso que éste ha de dar, previo a toda tentativa lírica, es, necesariamente, el que ejemplifican todos y cada uno de los análisis efectuados por A. Machado y atribuidos a Mairena.

En segundo lugar, ilustran también el proceder mismo de A. Machado, tanto en la elaboración de su ideario estético como, sin duda, en la de su creación poética. Si con respecto a su ideario los ejercicios dejan ver un pensamiento asistemático, que aborda en diferentes ocasiones y con distintos enfoques la misma cuestión, desde el punto de vista en la creación poética, A. Machado nos dice, con sus ejercicios, no sólo cuál ha de ser la actitud del poeta, sino también cuál fue su propia postura de poeta frente a la lengua común, a saber, la de analizarla consciente y pacientemente, hasta conocer la estructura de los elementos que habría de reestructurar para la expresión justa y clara de su sentimiento. 
